\title{
25 A FRAMEWORK FOR IMPROVING THE QUALITY OF OPERATION IN A VIRTUAL ENTERPRISE
}

\author{
P.M. (Nel) Wognum*, Edward C.C. Faber \\ University of Twente, The Netherlands
}

This paper presents a framework for improving the quality of operation of a virtual enterprise. The framework integrates the key aspects facilitating and supporting collaboration between people participating in a virtual enterprise. These aspects encompass not only the processes in a virtual enterprise, but also the environment, people and means, and organisation. The multiplicity of contexts that have to be taken into account in assessing collaboration in a virtual enterprise is explicitly addressed. The framework is a result of the Esprit 23286 project FREE.

\section{INTRODUCTION}

The performance of a virtual enterprise depends to a large extent on collaboration between the people participating in the virtual enterprise, as is commonly agreed upon in the literature (see e.g., Pinto \& Pinto, 1990)). Management of collaboration in a virtual enterprise, however, is highly complex, since people from multiple disciplines and functions have to work together to achieve a common goal. Although such collaboration resembles Concurrent Engineering within an organisation, the differences in culture and language - local, organisational, and technical - are often much larger in a virtual enterprise. Moreover, people that have to collaborate in a virtual organisation are subject to often largely different contexts that influence their way of working. In addition, the work has to be performed at geographically dispersed sites, while communication tends to decrease dramatically with increasing distance (Allen, 1977).

Our knowledge of how to manage collaboration in a virtual enterprise is still very limited, which can be observed from the limited success rate of existing collaboration efforts (Harrigan, 1985; Littler et al., 1995; Wildeman \& Stoffelen, 1996). In addition, a large part of recent research efforts has been devoted to identifying relationships between initial conditions and success or failure of a virtual

- Corresponding author address: University of Twente, Faculty of Technology and Management, Department of Technology and Organisation, P.O. Box 217, 7500 AE Enschede, The Netherlands, tel.: +31 534893736, fax: +31 53 4892159, E-mail: P.M.Wognum@sms.utwente.nl

The original version of this chapter was revised: The copyright line was incorrect. This has been corrected. The Erratum to this chapter is available at DOI: 10.1007/978-0-387-35577-1_37 
enterprise, such as the relationship between collaboration and success. Knowledge on how to organise and manage collaboration is still very limited, however. Organisation and management of collaboration in a virtual enterprise requires a thorough understanding of the variables that are amenable to intervention in case of insufficient performance (George \& Farris, 1998). To build the necessary knowledge, we need suitable models and tools in which the key areas are represented that influence collaboration in a virtual enterprise.

In the Esprit 23286 project FREE (Fast Reactive Extended Enterprise), a framework has been developed for improving the quality of operation in a virtual enterprise. This framework is considered a first step in developing methods, tools, and techniques that support management of a virtual enterprise in improving collaboration and, thus, the quality of operation. The focus of the FREE project has been on virtual enterprises that exist only for the duration of a project on the development of a complex one-of-a-kind product.

In this paper the framework will be presented including an example that illustrates the use of the components of the framework. The FREE project will be described in the following section including a brief introduction to the components that have been developed in the project. After that the FREE organisational model will be discussed in more detail. The example and a summary will conclude this paper.

\section{THE FREE PROJECT}

The FREE 23286 project FREE (Fast Reactive Extended Enterprise) has been performed from January 1996 until January 1998. Its goal was to develop management tools and methods to improve the way of working in a virtual enterprise. In satisfying this goal all key aspects that facilitate and support collaboration in a virtual enterprise had to be identified.

In the FREE project, a virtual enterprise is viewed as an organisation. Therefore, all aspects that characterise an organisation have been taken into account. These aspects encompass the environment of a virtual enterprise, the shared processes, the people and means, and the organisation. In improving collaboration in a virtual enterprise all aspects have to be taken into account in an integrated way to support deliberate choice for organisational areas to be improved and thus prevent local optimisation.

The project has led to four deliverables:

1. A generic organisational model (FREE organisational model (Wognum \& Faber, 1998)), in which potential problem areas with respect to collaboration in a virtual enterprise are represented. The model is built from key elements and relationships that allow managerial intervention. The purpose of the model is to describe an existing virtual organisation and to provide a scoping mechanism for problems that have been detected, which means that the model supports selection of the relevant part(s) of a virtual enterprise that need(s) to be improved.

2. A Capability Assessment Framework (FREE-CAF (Lebrun et al., 1998a; Lebrun et al., 1998b; Lebrun et al., 1998c)) that supports assessing current 
practices in a virtual enterprise and selecting applicable key practices at several maturity levels both in a virtual enterprise and in its partner organisations. Assessment of partner organisations is aimed at identifying their capability to participate in the virtual enterprise. The FREE-CAF provides support in deciding on what to change in the selected part of the virtual enterprise. It is based as far as possible on the CMM theory, structure and terminology developed by SEI-CMU. The FREE-CAF contains an extensive library of key practices for a virtual enterprise and its partners.

3. A Performance Measurement Method (FREE-PMM (Arfman et al., 1998)) that supports measuring the performance of (collaboration in) a virtual enterprise in operation. The method applies both to the performance of an improvement project and to the daily operation of a virtual enterprise. The FREE-PMM addresses the most important issues concerning the definition and use of a performance measurement method. It consists of a methodology to develop a performance measurement method for a specific virtual enterprise as well as practical examples of the use of such a method.

4. An Improvement Framework (FREE-IF (Hoekstra et al., 1998)) that provides an integrated method for improving a virtual enterprise in operation. In the framework all other deliverables of the FREE project have been integrated. The FREE-IF provides the starting point for improving the quality of operation of a virtual enterprise. It provides a default scenario that has to be adapted to specific types of a virtual enterprise.

5. A specific version of the FREE deliverables for SMEs has been developed (Gosset et al., 1998a; Gosset et al., 1998b). The SME adaptation contains simplified versions of the FREE-CAF, the FREE-PMM, and the FREE-IF based on concrete experiences. The FREE organisational model has played an important role in structuring the capabilities for SMEs.

The deliverables of the FREE project are based on extensive knowledge of the FREE project partners on projects performed in partnership and on the literature on virtual enterprises. The deliverables have been validated by peer reviews. The deliverables have to be evaluated and refined by applying them in practice. This will be part of follow-up projects.

The deliverables of the FREE project can be used in a continuous cycle of measurement, analysis, redesign, and improvement. This cycle, as depicted in figure 1 , is based on the well-known Shewhart-Deming cycle as described by Crosby (1979). The FREE-IF is based on this improvement cycle.

A problem, for which an improvement initiative is started, can be detected in two ways: 1) by applying performance measurement, and 2) by people at any level of the virtual enterprise. After the decision has been made to tackle the problem, the plan phase starts. In this phase, an improvement goal, a so-called business issue, is defined. The scope of improvement is determined by applying the FREE organisational model. The model relates business issues to specific model elements. These model elements have to be instantiated for the specific case at hand. The model elements in turn are related to specific key practices in the FREE-CAF and to performance measurement indicators in the FREE-PMM. By selecting applicable key practices and performance indicators, improvement initiatives can be defined. The do phase can then start with the definition and execution of one or more 
improvement projects. This phase is alternated with the check phase in which performance measurement is applied to check the progress and effects of the improvement efforts. Measurement may lead to the act phase. In this phase, the improvements are 1) accepted, when the improvement goals have been achieved, 2) continued, when the improvement project is still on the right track, or 3) adapted, when large discrepancies exist between the improvement goals and the actual achievements. In the last case the cycle starts again with the plan phase.

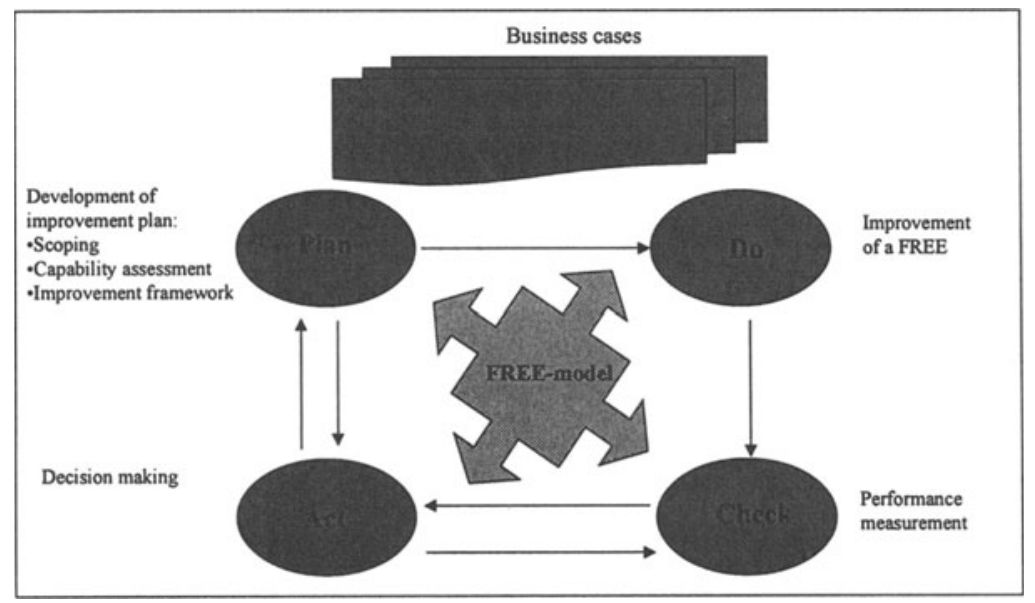

Figure 1 - The FREE improvement cycle

\section{THE FREE ORGANISATIONAL MODEL}

In the FREE project a virtual enterprise is considered as a special case of a 'normal' organisation. Therefore, the FREE organisational model is based on existing models in organisational science. In the FREE project, emphasis has been put on collaboration that is generally considered as a primary success factor. In the next subsection collaboration in a virtual enterprise will be discussed followed by a presentation of the FREE organisational model.

\section{Collaboration in a virtual enterprise}

Collaboration is a vague notion that is hard to define. Different definitions have been given for collaboration (see e.g., Pinto \& Pinto, 1990). To be able to understand collaboration the constituting elements of collaboration should be identified. In the FREE project we have defined collaboration in terms of structural alignment and communication.

Communication is viewed as an essential part of collaboration. Especially informal communication is an important indicator of the level of collaboration (Pinto \& Pinto, 1990). Communication is part of the processes in an organisation. 
Through communication activities information is exchanged within and between transformation activities, such as management activities, primary activities, and support activities. Communication encompasses communication between the people participating in the virtual enterprise, i.e., communication between the partners, and communication between a virtual enterprise and its environment. Communication between a virtual enterprise and its environment consists of communication between a virtual enterprise and its customers, its competitors, legal bodies, etc., but also with the parent organisations of partners.

Processes in an organisation, including collaboration, depend on structural alignment between organisational elements. Structural alignment is a property of relationships between elements of an organisation which can be expressed in terms of integration between these elements and mutual fit (see e.g., (Galbraith, 1977; Paashuis, 1997)). In a virtual organisation, structural alignment means alignment between partners in a virtual enterprise, and between partners and their parent organisations, and between parent organisations.

The relationship between collaboration on the one hand and structural alignment and communication on the other can be viewed as a two-way relationship. First, collaboration can be defined as the outcome of structural alignment of organisational elements. Alignment between organisational elements consists, e.g., of the following:

- Alignment of goals both within an organisation and between organisations;

- Alignment of goals and the environment of a virtual enterprise;

- Alignment of activities both within one process and between processes;

- Alignment of people in terms of skills, interpretation frameworks, attitudes, or culture;

- Alignment of means between the partners in a virtual organisation;

- Alignment of organisational arrangements between a virtual organisation and its partners and between partners.

For example, large differences between organisational arrangements may lead to different expectations, people waiting for each other and much time lost.

Second, collaboration depends on communication. Without communication, people will hardly be able to collaborate. Communication also depends on the level of structural alignment. For example, it is obvious that insufficient alignment between communication support tools hampers communication. Collaboration in this case will be far from optimal.

Vice versa, structural alignment and communication can be viewed as an outcome of collaboration. Collaboration influences the level of structural alignment and may lead to changing the organisational elements involved. Communication often provides the way to influence structural alignment. For example, communication of differences in goals may lead to a better alignment of those goals, while communication of the organisational arrangements that people have to commit to in their parent organisations may lead to better understanding and, consequently, to better alignment of people's attitudes. Collaboration also directly influences communication. Especially informal communication is an indication of the level of collaboration (Pinto \& Pinto, 1990; Kahn, 1994).

In the FREE organisational model, structural alignment between the organisational elements in a virtual enterprise is modelled. A desired level of 
structural alignment may be achieved by implementing key practices in a virtual enterprise and the partner organisations involved. Such key practices are modelled in the FREE-CAF. The performance of communication in a virtual enterprise, on the other hand, can be measured by applying the FREE-PMM. The relationships between the FREE organisational model, the FREE-CAF, the FREE-PMM, the processes in a virtual enterprise, including communication and collaboration as part of those processes, is depicted in figure 2.

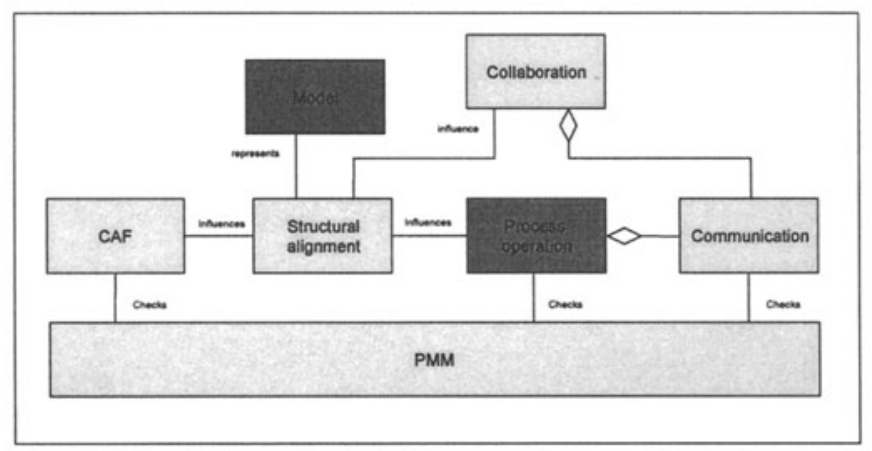

Figure 2 - Coherence between the FREE organisational model, the FREE-CAF, and the FREE-PMM.

\section{The FREE organisational model}

The FREE organisational model is based on the process based contingency model of organisations developed at the University of Twente (Hulshof, 1976; Krabbendam, 1988; Boer \& Krabbendam, 1993; Weerd-Nederhof, 1998). The model is used to describe and analyse several different business situation in many Master and Ph.D. projects (see e.g., (Boer, 1991; Schuring, 1997; Paashuis, 1997; Wognum et al., 1997)). The FREE organisational model explicitly identifies the different contexts involved in a virtual enterprise. These different contexts complicate collaboration in a virtual enterprise. The contexts consist of the virtual enterprise itself and those of the partner organisation. In figure 3, the different contexts have been depicted. The model elements and relationships have been represented in Object Modelling Technique (OMT) developed by Rumbaugh et al. (1991).

The virtual enterprise is represented as an organisation with its own goals, strategy, environment, and product to be developed. The product must satisfy (potential) customer needs that are derived from the environment. The goals and strategy of a virtual organisation must be aligned with the customer needs to be satisfied. The product may consist of parts.

The virtual enterprise consists of two or more partners, each of which is part of a parent organisation. The product and its parts are developed and produced by the partners of the virtual enterprise.

Each parent organisation is also an organisation with its own goals, strategy, and environment. For collaboration in a virtual enterprise especially the collaboration 
strategy and goal are important. The goals and strategy of a partner should be sufficiently aligned to the goals and strategy of the virtual enterprise.

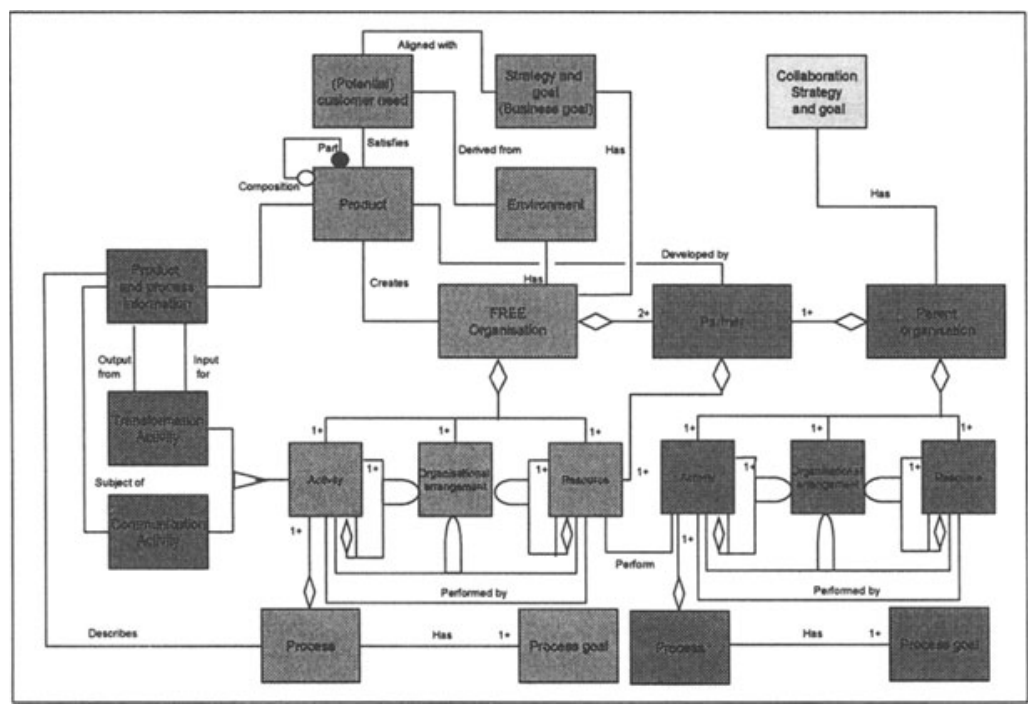

Figure 3 - The FREE organisational model

To achieve the goals of the virtual organisation processes have to be performed both in the virtual organisation and each of the partners. The partners perform the primary processes controlled and supported by local management and local support processes. In the virtual organisation shared processes are performed that have been specifically designed for the virtual enterprise or have been specifically selected from partners. These shared processes are the strategic, adaptive, and operational management processes and the support processes. The FREE project has specifically focused on the adaptive (improvement of the quality of operation) and operational management processes (daily planning and control) and the support processes. The support processes are, e.g., team building, resource management, and product data management. Communication in the primary process has been included in the FREE project's scope, while the primary process itself has been left out, since each partner is considered to be capable of performing the necessary transformation activities in the primary process. After all, partners have been selected because of their competence.

In figure 3 , the organisational elements are shown characterising a virtual enterprise and its partner organisations. These elements are the processes performed by a virtual enterprise and by its partners, the resources needed to perform the processes and the organisational arrangements to co-ordinate and divide the work. Processes consist of one or more activities, which in turn may consist of lower-level activities. Activities are performed by resources, which are the people and means in an organisation. Organisational arrangements consist actually of relationships between organisational elements:

- Relationships between activities, such as the activity and process structure; 
- Relationships between people and means, such as the working environment and the technological environment;

- Relationships between activities and people and means, such as the assignment structure that consists of the assignment of tasks, responsibilities, and authorities to people. The structure of meetings and teams are part of this assignment structure.

Organisational arrangements can be both formal and informal. Formal arrangement can be stated in procedures that are often officially written down in quality handbooks. Other arrangement may consist of generally accepted working routines that are not necessarily part of a quality handbook. A part of the arrangements is embedded in the culture of an organisation.

Activities can be specialised in transformation and communication activities. Transformation activities transform input information on the product and the process into output information. Communication activities transfer this information from one activity to the other. As can be seen in figure 3, the information on the product and process is processed and delivered by both the virtual organisation and the partners involved. This means that procedures, standards, formats, etc., agreed upon in the virtual enterprise are affected by procedures, standards, formats, etc. that exist in the parent organisations.

People performing processes both in the virtual enterprise and the parent organisation they belong to have to deal with different contexts, namely the virtual enterprise and the parent organisation. As part of the virtual enterprise, they have to conform to the organisational arrangements of the virtual enterprise. On the other hand, as part of the parent organisation, they also have to conform to, or at least are influenced by, the organisational arrangements of the parent organisation. Large differences between the organisational arrangements of the virtual enterprise and parent organisations may lead to dual loyalty problems of the people involved.

The means that are used to perform the processes to achieve the goals of the virtual enterprise are also delivered by parent organisations. Large differences between the means, such as word processors, CAD systems, or document management systems may severely hamper communication and collaboration.

The blackboxes of activities and organisational arrangements can be opened again as has been indicated in the text. For reasons of space limitations we leave out the figures with the lower-level elements. Readers interested in the refinements are referred to the FREE organisational model document (Wognum \& Faber, 1998).

At an abstract level, the FREE organisational model represents the potential problem areas that can be found in the literature and that have been observed in practice. The model is applicable to virtual enterprises collaborating on the development of a new product. Each product development project is different and requires specific activities, knowledge and skills, means, and organisational arrangements to achieve the goals. The model has to be instantiated for each specific virtual enterprise to be able to denote problem areas that are specific for that particular virtual enterprise. The model helps to systematically list the classes of problems that may occur and thus helps to identify existing problems. In the FREE project the model served as a scoping mechanism. It links specific business issues to model elements, which, in turn, are linked to key practices and performance 
indicators. The example given below illustrates the use of the model as a scoping mechanism.

\section{AN EXAMPLE}

To be able to use the model as a scoping mechanism, the problem that has been observed needs a preliminary analysis to be able to define the desired situation in terms of goals to be achieved. The following steps can be performed:

1. Identify the collaboration problem that has to be solved. This problem may have been identified by means of the FREE-PMM that focuses on measuring the performance of process operation with a specific focus on collaboration.

2. Define the process that contains the problem. This process will be called the focus process. The focus process will most often be a transformation process, e.g., a management process, a (particular phase in the) primary process, or a support process.

3. Define the desired situation that will solve the problem. The desired situation can be considered as the business issue for an improvement initiative.

4. Identify which part of the organisation must be improved. To support this task, business issues have been related to model elements that represent the organisational parts that may be addressed. Select the model element(s) that are most relevant for the situation encountered.

5. Analyse the problem situation in depth by means of capability assessment. To this end, select possibly relevant Key Process Areas (KPAs) by traversing the links from model elements to KPAs. Select from the list of KPAs the most relevant KPAs to solve the problem at hand. The goals stated for each KPA (Lebrun et al., 1998c) may support the selection task.

6. Define improvement actions. The FREE-IF (Hoekstra et al., 1998) will support this task.

7. Select appropriate performance indicators to be able to check the performance of improvements from the selected KPAs and by traversing the links from model elements to the FREE-PMM (Arfman et al., 1998).

Below, we will give an example of the steps given above.

Suppose, we have observed that documents to be reviewed in a collaborative product development project are too late. This problem will contribute to passing deadlines, which may lead to increased costs. The business issue to be chosen is 'Reduction of product development duration'. This business issue can be refined into lower-level business issues that are presented in Table 1.

Each of these business issues may be further refined. For example, resources availability can be refined into the availability of people and means, while the issue on interfaces can be refined to incorporate the different types of organisational arrangements.

We will choose the business issue 'improved interfaces', because we have observed that on this point some improvements may be necessary. From the issues on 'Improved interfaces' we choose 'Process and activity structure' from the model elements, since we have the impression that tuning of activities between partners could be improved. 
Table 1 - Business issues on reduction of product development duration

\begin{tabular}{|l|}
\hline Reduction of product development duration \\
\hline Alignment of strategy and goals \\
\hline Enhanced reusability of product parts \\
\hline Improved project control \\
\hline Improved resource availability \\
\hline $\begin{array}{l}\text { Improved interfaces between a virtual enterprise and parent } \\
\text { organisations }\end{array}$ \\
\hline
\end{tabular}

The next step is to find applicable Key Process Areas that can be applied to improve the quality of operation of the virtual enterprise. From the list of KPAs that relate to 'Process and activity structure' we choose 'Shared process definition'. This KPA deals with the development, implementation, and maintenance of interoperable processes. From this point on we can follow the guidelines of the FREE-CAF. In the FREE-PMM suitable performance indicators can be found to monitor the effectiveness of the improvement actions.

The steps we have shown can support a business analyst in identification, analysis, and improvement definition of problems with respect to the quality of operation of collaboration in a virtual enterprise. Our approach does not yet support the improvement process, but can be used to plan and monitor the effectiveness of the improvement. The strong point is that it supports an analyst and people participating in a virtual enterprise that are involved in the problem domain, with a systematic and structured list of business issues and KPAs that can solve these issues. In our view, people in an organisation often have an idea of the problem at hand, but require some support in finding its causes and corresponding solutions. The solutions we provide through the model elements and the KPAs are sufficiently generic to be applicable to a large set of problem areas in inter-organisational product development. On the other hand, they are expected to help people to define improvement initiatives that are specific for the situation at hand.

\section{SUMMARY AND FURTHER WORK}

We have presented a framework for improving the quality of operation of a virtual enterprise with a specific focus on collaboration, which is considered a key success factor of a virtual organisation. The framework has been developed in the Esprit 23286 project FREE (Fast reactive Extended Enterprise) that finished in january 1999. The components of the framework have been briefly described. One of the components has been described in more detail, namely the FREE organisational model that represents the key problem areas with respect to collaboration. The model is based on an existing model from organisational science, which is the process based contingency model of organisations, developed at the University of Twente. This model identifies not only the (complex set of) processes in an organisation, but also the people and means that perform the processes, the organisational arrangements that divide and co-ordinate the processes in terms of 
relationships between the processes, people and means, as well as the environment, strategy and goals that have to be satisfied.

The model forms a central part of the deliverables of the FREE project, because it provides a structured and systematic index into the Key Process Areas in the FREE-CAF and to performance indicators for specific business issues. A business analyst, with the help of people participating in a virtual enterprise, can select business issues applicable to the problem at hand, select model elements that relate to the part of the organisation that encounters the problem, and select appropriate KPAs and performance indicators. These KPAs and PIs have to be further tuned to the specific situation.

The FREE model and other deliverables of the FREE project are based on extensive knowledge of the FREE project partners on multi-site project management, organisation, and communication. The deliverables are ready to be tested in practice. To plan and monitor experiments and further development, a FREE Special Interest Group was recently established. Application of the framework is expected to contribute to the body of knowledge needed to refine the components of the framework. Such refinements are necessary to support management of collaboration in different types of virtual enterprises.

\section{Acknowledgements}

The work reported in this paper has been partly sponsored by DGIII of the European Commission. The author thanks all partners of the FREE project who have contributed to the development of the framework. The partners were Signaal, Thomson, Dasa, Cap Gemini, Adepa, Seaview, MP Consultants, EsoCE.

\section{REFERENCES}

1. Allen TJ. Managing the flow of technology, MIT press, Cambridge, 1977.

2. Arfman M, Hof C, Wagenberg M. van. FREE performance measurement method. Deliverable 142 , ESPRIT project 23286 FREE, 1998.

3. Boer H. Organising innovative manufacturing systems. School of Management Studies, University of Twente, Enschede, the Netherlands, 1991.

4. Boer $\mathrm{H}$, Krabbendam JJ. Inleiding organisatiekunde (Introduction to organisational science), University of Twente, The Netherlands, 1993.

5. Crosby PB, Quality is Free: the art of making quality certain. McGraw-Hill: New York, 1979.

6. Galbraith JR, Organization design. Addison-Wesley Publishing Company, Inc. Philippines, 1977.

7. George VP, Farris G. "Performance of alliances: formative stages in their lifecycle and changing organisational and environmental influences". In Proceedings of the R\&D Management Conference on Technology Strategy and Strategic Alliances, Avila, Spain, 1998.

8. Gosset $P$, Wagenberg $M$ van, Lebrun J. FREE SME Adaptation. Vol. 1: Overview and guidelines to transpose the FREE methods to SMEs. Deliverable 202, ESPRIT project 23286 FREE, 1998a.

9. Gosset P., Wagenberg M van, Lebrun J. FREE SME Adaptation. Vol. 2: Tailoring and implementing the FREE methods. Deliverable 202-2, ESPRIT project 23286 FREE, 1998b.

10. Griffin Abbie, Hauser John. Integrating R\&D and marketing: a review and analysis of the literature. Journal of Product Innovation Management 1996; 13: 191-215.

11. Harrigan KR. Strategies for joint ventures. Lexington books, Lexington, MA, 1985.

12. Hoekstra A, Hoogeboom M, Oei H. FREE Improvement Framework. Deliverable 152, ESPRIT project 23286 FREE, 1998. 
13. Hulshof AH. Syllabus college organisatiekunde (Syllabus college organisation science). Technische Hogeschool Twente, vakgroep Technische Bedrijfskunde, Enschede, the Netherlands, 1976.

14. Kahn KB. Marketing's integration with other departments. Dissertation Virginia Polytechnic Institute and State University, 1994.

15. Krabbendam JJ. New technologies and organisational measures. Ph.D. Thesis, University of Twente, Enschede, the Netherlands (in Dutch), 1988.

16. Lebrun J, Gosset P, Pallot M, Roux P, Gandelot D, Vannier M. FREE Capability Assessment Framework (FREE-CAF). Volume 1: Overview. Deliverable 132-1, ESPRIT project 23286 FREE, 1998a.

17. Lebrun J, Gosset P, Pallot M, Roux P, Gandelot D, Vannier M. FREE Capability Assessment Framework (FREE-CAF). Volume 2: Reference Manual. Deliverable 132-2, ESPRIT project 23286 FREE, $1998 \mathrm{~b}$.

18. Lebrun J, Gosset P, Pallot M, Roux P, Gandelot D. FREE Capability Assessment Framework (FREECAF). Volume 3: Reference Model. Deliverable 132-3, ESPRIT project 23286 FREE, 1998c.

19. Littler Dale, Leverick Fiona, Bruce Margaret. Factors affecting the process of collaborative product development: a study of UK manufacturers of information and communications technology products. Journal of Product Innovation Management 1995; 12: 16-32.

20. Paashuis, V. The organisation of integrated product development. Ph.D. Thesis, University of Twente, Enschede, the Netherlands, 1997.

21. Pinto MB, Pinto JK. Project team communication and cross-functional cooperation in new program development. Journal of Product Innovation Management, 1990; 7: 200-212.

22. Rumbaugh J, Blaha M, Premerlani W, Eddy F, Lorensen W. Object-oriented modelling and design. Prentice-Hall International, Inc., Englewood Cliffs, New Jersey, 1991.

23. Schuring RW. Process modelling of dynamics in organisations. Ph.D. Thesis, University of Twente, Enschede, the Netherlands (in Dutch), 1997.

24. Weerd-Nederhof PC de. New product development systems, operational effectiveness and strategic flexibility. PhD thesis, University of Twente, Enschede, 1998.

25. Wildeman Leo, Stoffelen Richard. Alliances and networks of the next generation. KPMG report, KPMG Alliances Networks \& Virtual Organisations, Amsterdam, the Netherlands, 1996.

26. Wognum Nel, Faber Edward. The FREE organisational model. Deliverable No. 122, ESPRIT Project 23286 FREE, 1998.

27. Wognum PM, Weerd-Nederhof PC de, Boer H. Challenges in organizing and managing integrated product development processes. Results of case studies into state-of-the-art in Concurrent Engineering in industry in the Netherlands. Research Report 97W-001/T\&O-001, University of Twente, Enschede, the Netherlands, 1997. 